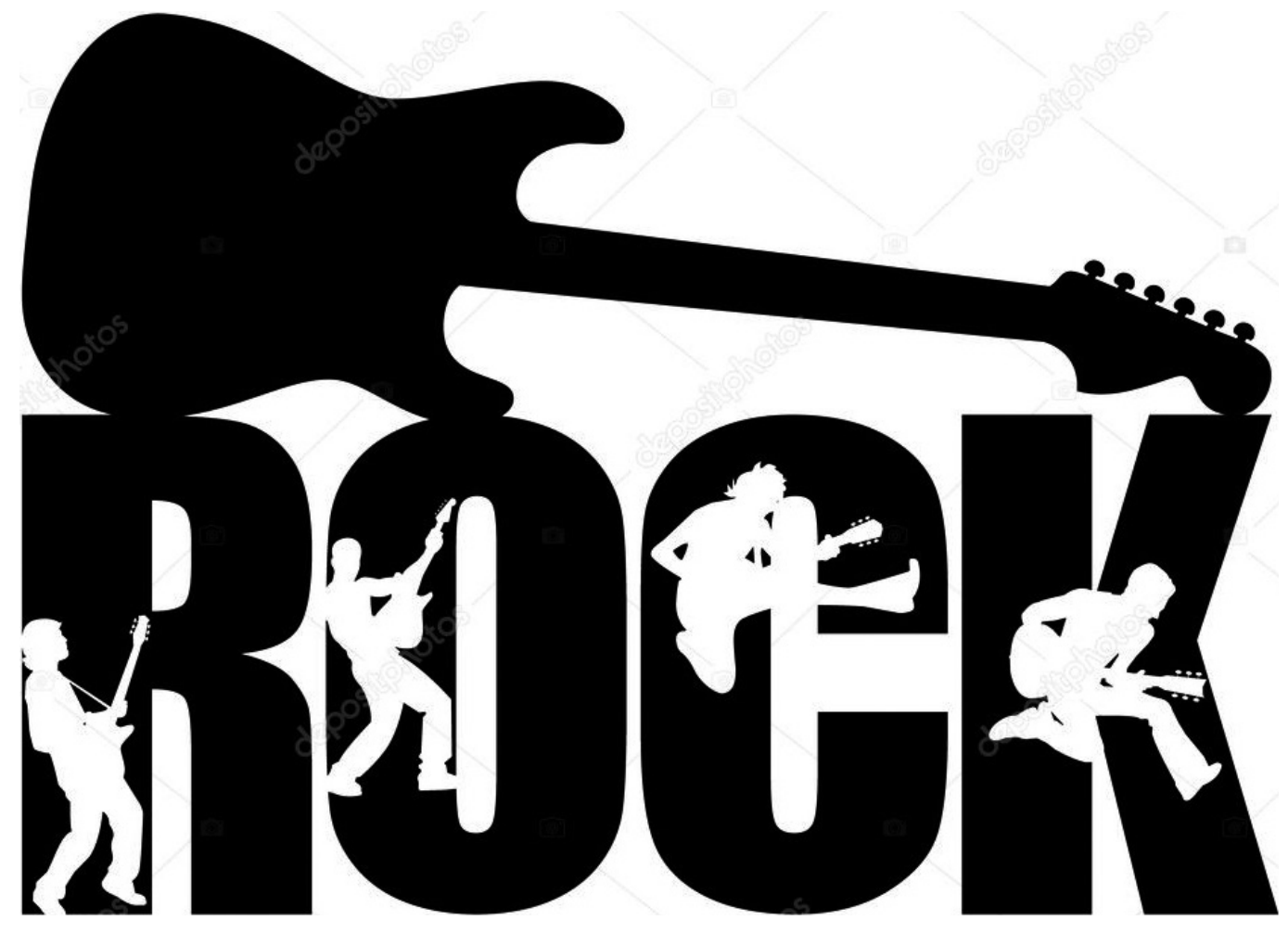

Rock and roll. Imagen de dominio público CCO. Tomada de: https://sp.depositphotos. com/2955539/stock-illustration-rock-word-with-guitar.html 


\title{
Charly García y el Síndrome The Wall: rock, política y parodia en la Argentina de los años noventa
}

\section{Charly García and The Wall Syndrome: Rock, Politics and Parody in the 90's Argentine}

Luis Diego Mora Morales

Universidad Latinoamericana de la Ciencia y la Tecnología

luis.moramorales@ucr.ac.cr

\begin{abstract}
Resumen
En Argentina, durante los años noventa, el peronismo cambió radicalmente de un populismo a un neoliberalismo liderado por Carlos Ménem, presidente de 1989 a 1999 . Charly García, un polifacético artista desarrolló nuevas estrategias multidisciplinarias a través de la parodia, la más importante metodología posmoderna de transgresión estética (Hutcheon, 2000). Se ofrecen varios acercamientos teóricos relacionados con el fenómeno económico latinoamericano desde tres álbumes de García que ejemplifican su evolución artística e ideológica: La hija de la lágrima (1994), Say No More (1996) y Demasiado ego (1999); que exploran las iteraciones de la parodia: binding, blending y banging (Chambers, 2012).
\end{abstract}

Palabras claves: Latinoamérica, Argentina, neoliberalismo, Carlos Ménem, Charly García, música rock, parodia, estrategias multidisciplinarias, transgresión estética

\begin{abstract}
In Argentina, during the Nineties, the Peronism changes radically from a populism to a neo-liberalism led by Carlos Ménem, president from 1989 through 1999. Charly García, a polifacetic artist develops new multidisciplinary strategies through parody, the main postmodern methodology of aesthetic transgression (Hutcheon, 2000). We will give some theoretical
\end{abstract}


approaches related with the Latin American economic phenomenon, aiming in three García's albums, that exemplify his artistic and ideological evolution: La hija de la lágrima (1994), Say No More (1996) and Demasiado ego (1999); exploring the iterations of parody: binding, blending and banging (Chambers, 2012).

Keywords: Latinoamérica, Argentina, neoliberalism, Carlos Ménem, Charly García, rock music, parody, multidisciplinary strategies, aesthetic transgression

\section{Introducción}

Cada artista crea sus propios precursores. Su trabajo modifica nuestra concepción del pasado, así como modificará el futuro.

J. L. Borges

Lo mío es una locura tan determinada que no puede salir mal.

Charly García, Programa 220, Canal 7, 1996

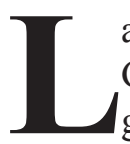
a premisa es contundente: Charly García ha sido la antena de la Argentina, dice Fito Páez, por él han pasado todas las fuerzas, las siniestras y las maravillosas ${ }^{1}$. Charly encarnó a través de la música rock la resistencia cultural durante las dictaduras de los setenta hasta principios de los ochenta, fue la voz en medio de la represión y la tortura, el narrador de su tiempo, amparado en una obra espléndida, original, cargada en aquella época de mensajes políticos a través del uso de la alegoría (Favoretto, 2014) para trasmitir su discurso, de una forma innovadora tanto en la producción

1 Desde un enfoque sociopolítico y cultural, las últimas cuatro décadas de la Argentina (de los setenta a los dos mil), la obra de Charly García cuenta con suficiente material como para elaborar una investigación transversal; lo que aportaría nuevas interpretaciones y aproximaciones teóricas. musical como en el contenido crítico de sus letras. A diferencia de otros músicos, como León Gieco y Mercedes Sosa, quienes vivieron el exilio durante el período dictatorial, irónicamente Charly tuvo más problemas con la policía en democracia. Como menciona su biógrafo, Sergio Marchi, "en los noventa comienzan los discos raros, incomprensibles, las internaciones, las declaraciones exasperantes, el genio desgarrado, el miedo a que se muera; comienza todo ese personaje que es una estrella de rock en problemas y que al público tanto le gusta ver" (El karma de vivir al sur).

En los años noventa Fito hablaba de "tiempos egoístas y mezquinos", Gieco advertía: "En esta globalización todos los globos se revientan", Calamaro exigía: "Señor banquero devuélvame el dinero". En cambio, Charly, durante el regreso de Serú Girán a los escenarios en 1993 respondía: "Lo hicimos por plata". ¿Es comprensible que un artista tan talentoso, considerado además un emblema social se transforme en un antihéroe político, un polémico ente mediático con tendencias neofascistas amparado en el marketing? ¿Qué representa esta transformación con 
implicaciones ideológicas y qué nos dice del ambiente en el que desarrolló su obra? Daremos algunas aproximaciones teóricas consecuentes con el fenómeno económico que por entonces pasaron la mayoría de los países latinoamericanos y se analizará la parodia como la principal metodología posmoderna de transgresión estética (Hutcheon, 2000), que produce arte trans-genérico (Chambers, 2012); dividido en tres grandes variaciones: parodia por vínculo (binding), por choque (banging) y por combinación (blending) ${ }^{2}$.

I. Binding 90-94: De Filosofía barata $a \mathrm{La}$ hija de la lágrima como parodia musical

Parody is repetition, but repetition that
includes difference.
Gilles Deleuze

Ahora el peligro es anónimo y no tiene uniforme. Se parece bastante a la maldad.

Charly García, Historias paralelas

(27-2-1999)

Como otras naciones de Latinoamérica, la Argentina vive el clima de lo que se llama "posmodernidad" en el marco paradójico de una nación fracturada y empobrecida (Sarlo, 1994), y Charly llega a esta década consolidado como artista, con el prestigio de todos los sectores. Desde el año 1983 preguntaba a su público en vivo: “¿qué más quieren, estamos en democracia?". Es en esa época que compone su tetralogía (Yendo de la cama al living, Clics modernos, Piano bar, Parte de la religión) que lo catapulta a la gloria como genio artístico. En Clics modernos muestra una

2 Chambers (2012) plantea dos subdivisiones para cada variación, que, por la complejidad teórica que acarrea y por la extensión del trabajo, se analizará en futuras investigaciones. evolución, no solo en estilo musical sino también en el discurso. Atrás quedaron las canciones protesta de Sui Generis y Posuigieco, el rock progresivo de la Máquina de hacer pájaros y las canciones lúgubres y depresivas (reflejo de una sociedad represiva) de Seru Giran. Charly se alzó como solista y como estrella.

En 1990 publica el álbum Filosofia barata y zapatos de goma, que, aunque no alcanza el nivel de éxito de sus discos anteriores, mantiene cierto ímpetu y sensibilidad 3 ; pero ya no satisface a los críticos ni al público, que comienzan a quejarse de la mediocridad asociada al abuso de drogas ilícitas ${ }^{4}$ ¿Es el éxito lo que genera esta actitud? ¿Se acabó el talento o hay otras razones? ¿A quién le canta Charly ahora, cuál es su enemigo? Paradójicamente resulta más difícil protestar contra un blanco más abstracto: la depresión económica. Como menciona Wilson (2001), "pareciera que, para transgredir, en esta época, ya no es necesaria la metáfora, la alegoría o la codificación del mensaje -que definieron el rock nacional de los setenta/ochenta sino que es necesario un registro visceral, obsceno y degradante" (p. 166).

Los explosivos saqueos de la hiperinflación de 1989 indicaron el surgimiento de síntomas de anomia, debilidad de la

3 Muestra de ello es la emotiva versión de Filosofia barata que Luis Alberto Spinetta interpreta en su concierto final Bandas eternas como homenaje a su viejo amigo. Al año siguiente aparece Cómo conseguir chicas, un compilado de canciones inéditas de diferentes épocas, a la manera de Spinetta con su disco Kamika$z e$. De hecho, el proyecto fallido entre Charly y Luis se iba a llamar Cómo conseguir chicas.

4 Charly es internado en esta década dos veces por drogadicción: en 1991 y en 1994. La "rehabilitación" en ambos casos no surte mayor efecto. 
sociedad civil, ruptura de los lazos de sociabilidad y la insolvencia de las instituciones estatales para establecer mecanismos simbólicos y pragmáticos de inclusión social. Pero la salida de esta crisis fue peor. El peronismo, nuevamente en el Gobierno desde 1989, cambió vertiginosamente su discursividad tradicional: del populismo distribucionista pasó a asumir las formas más radicales del neoconservadurismo, al iniciar la etapa conocida como menemista (Alabarces, 1997, p. 49). Después de una década cargada de contradicciones ${ }^{5}$, los

5 Una vez que finaliza el Proceso de reorganización, como se le conocía al período de gobiernos militares que impusieron la tortura y la desaparición de personas, el presidente Alfonsín es el encargado de realizar la difícil transición a la democracia. Una de sus primeras decisiones es abrir una investigación para aclarar las desapariciones y abrir una causa judicial contra los exdictadores. Como resultado de este proceso, se publica "Nunca más", un compendio de testimonios que, dirigido por Ernesto Sabato da una idea de las atrocidades vividas entonces. Se encarcela a la mayoría de líderes y comienza un duro proceso de reconciliación social. Sin embargo, la inestabilidad económica, resultado de los malos gobiernos lleva a adelantar las elecciones. De esta manera, Carlos Ménem se convierte en el segundo presidente elegido democráticamente, y se mantendrá en su puesto durante toda la década de los noventa, al establecer un patrón que marcará a toda la sociedad argentina. Paradójicamente, una de sus primeras medidas es dejar en libertad a los exdictadores, al abrir procesos de amnistía que tiran a la basura todos los esfuerzos por justicia para las víctimas y familiares de los desaparecidos. La indignación comienza a apoderarse de la sociedad, pero serían las medidas económicas neoliberales las que llevarían al país a una de las crisis más espantosas de la historia latinoamericana contemporánea. El Consenso de Washington establecía reformas neoliberales para todos los países latinoamericanos, impuestos a través del Banco Mundial y el Fondo Monetario Internacional bajo el apelativo de Programas de Ajuste Estructural. La justificación que se dio en el caso de Argentina fue que debía combatirse la hiperinflación heredada del período dictatorial, a través de lo que se llamó Ley de Reforma del Estado, que en términos prácticos privatizaba las empresas estatales. La otra gran medida fue la Ley de Convertibilidad, que colocaba el peso argentino al mismo valor que el dólar, lo cual derivó en un encarecimiento de los productos y años noventa, bajo el mando de Ménem impusieron el modelo neoliberal, el cual, como menciona Dowdy (2013),

Aims to maximize freedom by reducing citizenship to a rational choice model of atomized, possessive individualism. This conception ties all valences of freedom to the market, dismantles collective forms of organization and ownership, converts states into servants to capital, guts social safety nets and the public sphere, and relentlessly commodifies culture, including modes of resistance. (p. 9)

Este sistema neoliberal dentro de un gobierno democrático formal "asegura el poder político-económico y la independencia en la toma de decisiones administrativas respecto a los intereses específicos de los ciudadanos" (Pelfini, 1997, p. 40). La atomización social, provocada por la dictadura militar de los años setenta y más posteriormente por el fenómeno hiperinflacionario, incrementó la esfera de autonomía de los individuos. El discurso neoliberal, que no tuvo receptividad durante décadas en el cuerpo social, encontró a principios de los noventa, condiciones óptimas de permeabilidad (Ballaré et al., 1997). Este proceso se asocia con el fin de una etapa no solo económica sino también social y cultural (ídem).

En este contexto, el rock parece no tener efecto sobre el neoliberalismo, en

\footnotetext{
el cierre masivo de los pequeños y medianos productores, lo que abre una brecha social que, aunado a los préstamos internacionales con altísimos intereses produjeron una obscena deuda externa que daría como resultado el bloqueo de todas las cuentas bancarias en 1999, conocido popularmente como El Corralito. Esta crisis económica se extendió hasta el 2002.
} 
parte porque la política de globalización del posmodernismo dificulta la diferencia entre opresor/oprimido y sujeto/objeto (Wilson, 2011, p. 174). Ante este panorama, ¿qué sentido tiene hacer canciones alegóricas? Ya no se censuran las referencias negativas hacia el gobierno, de hecho, grupos como Bersuit Vergarabat son directos al criticar el mandato menemista con frases explícitas como "Menem se lo gana y no hablemos de pavadas, así son todos, traficantes, ¿y sino el sistema qué?" El rock chabón toma la bandera de la lucha social. "El rock chabón no es ni el rock de los ganadores, ni el de los dueños de la ciudad, sino el de las víctimas jóvenes de una reestructuración social violenta" (Semán y Vila, 1999, p. 248). En este sentido, "cuando el rock "oficial" deja de contestar, el rock chabón contesta nuevamente" (p. 253). Como ejemplo, Los Fabulosos Cadillacs, cantan "Soy la voz de los que hicieron callar por el solo hecho de pensar distinto", pero en medio de este difícil ambiente, "están deliberadamente confundidos el resistente antidictatorial y el marginal urbano, la policía y la dictadura" (p. 254). Como menciona Wilson, "La causa de insatisfacción en los noventa y dos mil es la depresión económica y el malestar resultante, un fenómeno mucho más abstracto y difuso, no tan fácil de señalizar o acusar" (p. 175).

Charly García, consciente de ello, cambia de estrategia: en vez de alegorizar como en los ochenta la situación socioeconómica de su país, la parodia, no solo con su obra sino con su vida, en una mezcla performática que involucra una serie de prácticas posmodernas; como dice Hutcheon (2000): “A major way that music can comment upon itself from within (as opposed to relying on accounts of precompositional planning) is through parodic reworkings of previous music" (p. 3). Contrario a Bakhtin, Hutcheon propone que la parodia no se limita a la literatura sino a todas las artes, y se opone a la perspectiva de Margaret Rose, quien se enfoca en la incongruencia, la discrepancia y discontinuidad, lo cual no se adecúa a las formas de parodia del siglo XX. Para Hutcheon, "It is not a matter of nostalgic imitation of past models; it is a stylistic confrontation, a modern recoding which establishes difference at the heart of similarity" (p. 8). En este sentido, manejaremos la definición de parodia propuesta por Chambers (2015):

Parody is a technique, probable hardwired in all of us that tweaks, rechannels, transforms, or invents artistic conventions by banging, binding, or blending material into paired, unlikely contrasts. The result is art that is widely dualistic. Because of the upheavals it creates, the parodic technique is the principal source of technical innovation and change in all the arts, the fountainhead of new genres and modes as well as the core of many masterpieces. Parody is the art that plays with art. (p. 25)

La principal característica de la parodia es ser trans-genérica: "As a single technique applied to literature, to music, or to visual arts, parody consists of three major refinements or iterations that create contrasts by banging, binding, and/or blending disparate, incongruous, or antithetical subject matter" (Chambers, p. 189). Es decir, no se limita a un solo género o campo de acción, sino que se mueve a través de iteraciones, 
"the hallmark of parody is multi-stable art, meaning art that invites more than one interpretation or reading (p. 190).

Como bienvenida a los noventa, Charly García desata una gran polémica cuando incluye en su disco Filosofía barata y zapatos de goma (1990) una versión rockera del Himno Nacional Argentino. Desquiciada por la asombrosa variedad y multiplicación de los géneros, la cultura de los noventa devora, recicla y refunde sin la carga prejuiciosa de otros tiempos (Rossi, 1997, p. 649). Lo novedoso es cómo de esta manera el rock se instala como estrategia deconstructiva: "rock is a necessary object of critical investigation because it has frequently been mobilized, often negatively (as in the neo-conservatism that Grossberg critiques in We Gotta Get Out of This Place [1992]), as a discursive token in the ideological contest over what he calls the "national popular" (Hutcheon, p. 5). El cover del himno argentino establece una correspondencia diferente no solo con la pieza original sino con el contexto, se trata más bien de un acercamiento creativo a la tradición.

La provocadora pieza de Charly es una parodia que difiere de la sátira y de otras formas de criticismo o imitación de trabajos artísticos. Es lo que Chambers denomina binding (parodia por vínculo), donde "reflexivity refers to works that are aware of their own artiness... in which the terms of contrast are presented as alternatives in layers or nests" (p. 233). Estas capas generan contrastes en diferentes niveles, tal es el caso del himno en formato de rock que crea una refuncionalidad a partir de material artístico preexistente, con alusiones a otros autores, lecturas y normas, "as well as to the relationship between the text, or discourse, and its social context" (Rose, p. 82). Por tanto, no es una simple imitación o distorsión de la obra original, se trata de "disrealize the norms which the original tries to realize, that is to say, to reduce what is of normative status in the original to a convention or a mere device" (p. 83).

En los sesenta, Karlheinz Stockhausen ya alteraba las melodías de diferentes himnos nacionales (Hutcheon, p. 7), pero es innegable la profunda influencia que tuvo en Charly la versión del Himno de los Estados Unidos interpretada por Jimi Hendrix en el concierto de Woodstock en 1969, donde "modulation in the song from a parodic distortion of the mutilated glory of the American national anthem to the appropriately ironic military melody of "The Last Post" was obviously satirically intended" (p. 78).

La estética posmoderna en el ámbito de la música vendría a englobar las manifestaciones musicales que desmienten el paradigma ortodoxo y se caracterizan por una reutilización de los materiales del pasado desde una perspectiva irónica o un doble código, y por el surgimiento de discontinuidades en una obra que niega el ideal clásico de una unidad y coherencia sin fisuras (Kaiero, 2014, p. 382). Como parte de este cambio, Charly experimenta con lo que la crítica dio en llamar sus "discos raros" repletos de capas, la reversión paródica de sus canciones y el exceso de covers. Este fenómeno se hace evidente en su "ópera rock" La hija de la lágrima (1994), un disco conceptual donde emplea el ambient music de Brian Eno, con 
sonidos del entorno que inicialmente no habían sido generados con una intencionalidad artística y que son susceptibles de captarse, dependiendo del punto de vista, como sonidos frívolos o con un valor musical. A lo largo del disco encontramos incursiones de productos externos a la obra, entre ellos fragmentos de películas como Odisea Espacial 2001, de Stanley Kubrick y Sueños de Akira Kurosawa, así como ecos urbanos o agua derramándose. Estos elementos representan el reverso paródico de toda una construcción cultural metafórica. Los artistas posmodernos se interesan por rescatar estos elementos sonoros inútiles e insignificantes, que, al igual que un ready-made, pueden ser infinitamente reutilizados con funciones y significados diferentes (p. 360).

Para sus seguidores, acostumbrados a grandes éxitos, este trabajo resultó desconcertante, en parte debido a la presencia de piezas instrumentales y conceptuales que desilusionaron a muchos de sus fanes, poco habituados hasta entonces a la pluralidad de discursos o juegos de lenguaje parciales, sin una perspectiva global que procurara una definición "verdadera" de las cosas (Kaiero, p. 263). Para la presentación de este disco, Charly aparece con el pelo rubio, en homenaje a Kurt Cobain, quien se había suicidado apenas unos días atrás.

II. Banging 95-96: De Casandra Lange a Say No More como parodia mediática

The master's tools can be used to dismantle the master's house. Theodore Gracik

\begin{abstract}
¿Para qué voy a perder tiempo? Digo que estoy loco y chau. Si viene un careta que no tiene nada que hacer y ve un show mío $y$ yo estoy al repalo, y nunca vio un recital de los Who, va a pensar que soy loco.

Charly García, 1996
\end{abstract}

Say No More (1996) es la obra que resume la caótica filosofía de vida de García, y a partir de la cual justificará su trabajo posterior. A través de Say No More, no solo construye toda una mitología de sí mismo, también surge el tatotá (artista total): el que pinta, diseña la portada del álbum, lo produce y arregla; pero que, por encima de la música, aprende a sacar provecho de la polémica. Es aquí cuando el nivel de parodia se transforma en banging (parodia por choque), una variación que como explica Chambers "create and then undermine a set of expectations by slapping them with radical alternatives (p. 213); ejemplos de banging serían el teatro del absurdo, los happenings y el performance (p. 220).

El arte deja de ser meramente la música para convertir al artista en arte por sí mismo, tal como explica Charly en el documental El karma de vivir al Sur: "Yo inventé la estrella de rock en Argentina, si no hubiera sido más fácil ser detenido por la dictadura" (El karma de vivir al sur). El mito encarna una idea y la gente hace lo posible para que la realidad se le parezca (Pons, 2014, p. 19). El argentino se identifica con un personaje para huir de la realidad (p. 150); es justamente en esta década neoliberal que Maradona -al igual que Charly- se transforma en un antihéroe, cuando en pleno Mundial de Fútbol en Estados Unidos en 1994, se le expulsa por consumo de efedrina. "La Argentina 
necesitaba de un héroe trágico y lo encontró. La caída de un ídolo verdadero tiene la virtud de romper la ficción de la vida y transformarla, quiera o no, en un espectáculo público perverso. Lo que emerge con una fuerza especial es el significado de la tragedia como desempeño, como espectáculo público y como rito" (Alabarces, 1997, p. 67).

Del mismo modo que Maradona y García, Carlos Gardel encarnó ese mismo rol, ocupándose de moldear y construir la persona pública. Como menciona Ruffinelli (1997), “el personaje que se esboza, en sus estrenos sucesivos, también empieza a superponerse a la figura de la vida real. Dicho de otro modo, Gardel deja transparentar algunos rasgos personales, y a la vez el "personaje" que surge de estas películas acaba caracterizándolo a él mismo en todas sus demás actividades" (p. 92). En este sentido, el puesto que ocupa Charly en los años noventa no es más que una herencia trágica. "En 1935, Gardel podía ya darse el lujo (o el capricho, y hasta el acto de conjurar sus fantasmas interiores), transparentando su identidad moral a través de la música, y construyendo un personaje que es él mismo hasta en los últimos detalles" (p. 92). Acorde con los tiempos que le toca vivir, Charly se las ingenia para reinventarse, para adaptarse a las circunstancias de un modo completamente consciente:

Empecé a ver que, si yo era un músico, sólo, iba a ser más pobre, iba a ser más fácil de ser eliminado por la dictadura y una serie de inconvenientes terribles; y me iba a parecer más justamente a los aburridos. Entonces yo no, dije: pará, ¿cuál es el trabajo de una estrella de rock? Hacer quilombo, vean los aviones, tirar televisores, jte pagan para eso, es el mejor trabajo del mundo! Entonces empecé a decir estrella, estrella, hasta que se lo creyeron. (El karma de vivir al sur)

El clímax de este estilo paródico que experimenta Charly García en los años noventa se ve cristalizado en su "ideología" Say No More; "una manera de entender el arte desde cierto abordaje instantáneo, el constant concept, un pulso vital que no reconoce especulaciones; algo así como el Manifiesto Dogma creado por el cineasta Lars Von Trier pero trasladado a la música" (Del Porte, 2000, p. 27). De esta forma, Charly concibe un mundo propio a la manera de Floyd Pinkerton, el protagonista de la película musical The Wall, con sus fantasmas y demonios cada vez más explícitos y polémicos. El héroe mítico "necesita un enemigo, una misión, principios y un logo. Su rol es una parodia, un juego" (Favoretto, 2014, p. 144), y Say No More es un mini-sistema dentro del sistema, como afirma García en 1997. La polémica surge con las semejanzas que este "mini-sistema" presenta con el fascismo:

Lo mío de levantar el brazo como Hitler con el brazalete que parece el de Hitler es como decir: es el poder por el poder mismo. Yo estoy acá haciendo esto, pero no estoy apoyando a Hitler ni nada; es el poder de que yo soy el dios, pero porque sí. Es como decir sí porque sí, me chupa un huevo todo y no hay ningún otro tipo de explicación, si estás acá es porque te gusta a morir, y si no tomátela (El karma de vivir al sur). 
Al igual que Prince ${ }^{6}$, García usa la transgresión para generar un sentido de trascendencia, "He uses these techniques to create a form of possession cult based around his personality, drawing (often young) fans into the semi-fictional world he creates" (Till, 2010, p. 12). Parte fundamental de esta iconografía son sus "aliados", los fanes. El darwinismo social del neoliberalismo entraña tanto el problema de la alienación de los individuos en una competitiva búsqueda de la sobrevivencia material, como el problema de la ruptura de los referentes para las construcciones colectivas (Pons, p. 10). En este sentido, Charly refleja el triunfo de la posmodernidad, como celebración del individualismo en un imaginario: "he began as a complex form of packaging for his music to try to ensure its success, but has evolved and become interwoven into his work as a vital part of a multimedia whole" (Till, p. 14).

Los medios masivos, principalmente la televisión, se convierten en los noventa en el Gran hermano, que vive de citarse y parodiarse hasta el punto en que la repetición del procedimiento llega a despojarlo de todo sentido crítico (Sarlo, p.

6 "More than within theatre, film, opera, television or any other multimedia form of performance art, within popular music culture Prince is able to confuse the boundaries between the real and the imaginary, the concrete and the mythical. This enables him to involve, engage and interact with his audience by stepping off the screen or stage into the real world, and validate his artwork, through concerts and interviews, as being part of reality rather than fiction. This in turn allows him to adopt techniques usually seen within religions, as part of his work. It is as if he is creating a new religious movement as an artwork, with himself as the central author, text and performer" (Till 14).
99). Este proceso de tinellización ${ }^{7}$ de la cultura en los noventa establece un vaciamiento de contenidos mediáticos a través de programas cargados de humor sexista que viven del rating, y donde la incertidumbre es aniquilada por la cercanía que la televisión establece entre la parodia a lo parodiado (p. 99). De la misma manera, la prensa amarillista basa sus ventas en la generación de polémica, y en este contexto Charly pasa a ser un chivo expiatorio, el mejor vendedor de diarios, a través de las controversias a las que se entrega premeditadamente ${ }^{8}$. Como dijo Nito Mestre: "Charly trabaja para ese personaje y él lo dice: yo trabajo para ser número uno y ese es un trabajo extra aparte de ser músico; sino tendría menos trabajo. Y evidentemente toda la prensa lo alimentó" (El karma de vivir al sur).

Como parte de la apropiación mediática que establece el neoliberalismo, el presidente Ménem se aprovecha para sostener su popularidad: "Ménem inauguró un contacto político y cultural a través de los medios de comunicación que era inédito"

7 En referencia a Marcelo Tinelli, presentador argentino y empresario; gran referente del formato de programas televisivos de variedades, basado en concursos, bromas con cámara escondida y sketches.

8 Uno de los momentos más polémicos se vivió en 1996, cuando en un concierto se burló de un eslogan contra las drogas ("Sol sin drogas") promovido irónicamente por Maradona, cambiándolo por "Drogas sin sol”. En una entrevista a Crónica lo explica: "Si no pueden comprender que, por ejemplo, hacer un eslogan sobre algo tan serio da para hacer alguna humorada, la verdad es que, viste, no es lindo salir en la primera página de todos los diarios todos los días. Ellos tratan en realidad de hacerme creer que estoy loco cuando normalmente estoy loco, o no. Ellos realmente tratan de hacerme parecer un delincuente o alguien que está así, un loco que le da mal ejemplo a la juventud cuando en realidad no es así. Hay mala gente, y hay gente que ni siquiera escucha mi música ni se toma el trabajo de escucharla" (Crónica). 
(Quevedo, 1999, p. 215). De esta forma, los medios de comunicación se transforman en el arma más poderosa del sistema económico, cuyo objetivo más preciado consiste en redefinir el vínculo mismo entre medios y política (p. 217).

El juego paródico que establece conscientemente García con los medios alcanza niveles de golpe (banging) que dejan al espectador asombrado y aturdido, ávido de más consumo mediático. "The finest artists are those who can express themselves in as many media forms as possible because they can reach everyone -the young, the old, the elite, and the illiterate" (Ikwuemesi en Hutcheon, pp. 339-341). La dificultad para la audiencia es reconocer en esa estrella de rock una performance paródica, "while being aware that that self is itself a performance and must be judged as a performance (Pattie, p. 11). "Morirse joven también está previsto en un guión televisivo. Resistir ese mandato sería lo verdaderamente transgresor" (Alabarces, p. 51).

III. Blending 97-99: De Alta fidelidad $a$ Charly \& Charly como parodia política

No quedó ni un solo niño ni una sola niña en Hamelin, todos se dirigían como las ratas bailando detrás del flautista al son de aquella melodía... parecían como hechizados, una vez todos reunidos, el flautista sin dejar de tocar los llevó a una enorme gruta y los escondió allí a todos. Hermanos Grimm, El flautista de Hamelin

Con esta cita cierra el disco de 1999 Demasiado ego, en donde Charly se convierte en un flautista que "hipnotiza" con su música a los "aliados", escondiéndolos metafóricamente del menemismo; lo que provoca un estado de confusión y delirio donde se suspende toda la trama de referencias que articula el discurso, que impulsa el performer a saltar de un gesto sonoro a otro y de un material de una época a otro, sin reparar en la necesidad de establecer ningún tipo de coherencia (Kaiero, p. 331). Este disco en vivo, con el que cerró el último verano de los noventa (el 27 de febrero de 1999) fue el nivel de megalomanía llevado al extremo: más de un cuarto de millón de asistentes a orillas del Río de la Plata, auspiciado por el gobierno, un escenario apoteósico ideal para su nivel casi divino, auto-referenciándose constantemente. Parody is a form of autoreferentially, but that does not mean that it has no ideological implications (Hutcheon, p. 28). Por eso, en medio de este caos, invita al escenario a las Madres de la Plaza de Mayo, en un homenaje no exento de polémica, al interpretar paródicamente frente a ellas la canción Kill my mother.

Repite la lógica del álbum Estaba en llamas cuando me acosté (1995), grabado en vivo con una nueva banda a la que llamó Cassandra Lange (un disco compuesto casi por completo de covers del rock americano sesentero), Charly retoma lenguajes del pasado para someterlos a procesos de lectura-reescritura, que acaban dessedimentando los significados originales y "desatando" una libre proliferación de interpretaciones y sentidos completamente independientes (Kaiero, p. 389). Así, los covers dirigen nuestra atención hacia todos los aspectos periféricos y "externos" que antes habían pasado completamente desapercibidos: hacia la dimensión no sonora de las acciones musicales (p. 391). 
En este concierto multitudinario, el espacio social se concibe como un "afuera" o un no-lugar conflictual y performativo, en el que los diferentes discursos se interfieren y pugnan por imponer su punto de vista. La apertura a un espacio de interferencia genera una movilidad simbólica en la que las canciones circulan de un discurso a otro, pierden la significación que revestían en su contexto de origen, convirtiéndose en unos "indecidibles" o unos significantes vacíos carentes de una identidad fundamental, que pueden ser constantemente redefinidos en función del juego de lenguaje en el que irrumpen (Chambers, p. 393). Este tipo de parodia por combinación, o blending es de acuerdo a Chambers "the most subtle, complicated, and misunderstood component in the parodic arsenal (p. 243). No es de extrañar que la faceta "fascista" de Charly sea malinterpretada, puesto que la parodia por combinación "impersonate someone or something that is specific, identifiable, and definite, such as a public figure" (p. 243).

A pesar de su búsqueda consciente de fama y dinero, Charly vive la mayoría de estos años en una especie de búnker ${ }^{9}$, de la misma manera que el protagonista de The Wall, degradándose física y psicológicamente, hasta dar el paso definitivo para convertirse en una estrella de rock con tintes fascistas; en un país donde "las políticas implementadas consolidan definitivamente el proyecto fundacional de 1976 pero en democracia" (Mancebo, 1999, p. 193).

9 Su apartamento en el barrio porteño de Palermo estaba "intervenido" por el arte de Charly, con grafitis, videos caseros, instrumentos musicales, collages y pinturas desparramados por todos los rincones.
No debemos olvidar que, "As is the case with other American nations, Argentina is living out the condition of so-called postmodernity in the paradoxical setting of a nation that is fractured and impoverished" (Sarlo, p. 3). Mientras el presidente Ménem centraliza la seguridad policial y los mecanismos de disciplina (Pons 3), Charly se convierte en una figura pública que se auto-parodia, a partir de una re-apropiación del pasado (Hutcheon, p. 75): "a work which reflects a fundamental aspect of art that is at the same time a symptom of historical processes which invalidate the normal authenticity of primary forms" (Kiremidjian en Hutcheon, p. 36).

Este nivel de auto-referencialidad que establece García tanto en su vida privada como en sus apariciones públicas y por supuesto en sus recitales -cada vez más cargados de excentricidades y menos de música- es lo que Hutcheon denomina trans-contextualización, es decir, el arte no es solo producto del artista, sino una colaboración espontánea entre el artista y su audiencia (Wilson 180). Una frase que ejemplifica la parodia por combinación se puede escuchar en el disco Demasiado ego cuando, en medio de más de doscientas cincuenta mil personas, Charly se autoproclama el rey de la Argentina ("no el presidente, sino el rey", aclara), valiéndose de la parodia como "one of the techniques of self-referentially by which art reveals its awareness of the context-dependent nature of meaning, of the importance to signification of the circumstances surrounding any utterance" (Hutcheon, p. 85). 
Charly \& Charly (1999) es el último disco de García durante la década de los años noventa, grabado en vivo en la residencia presidencial argentina en Los Olivos, donde fue invitado por el presidente Ménem a cenar y dar un concierto privado, en uno de los actos paródicos más imprudentes, arriesgados y polémicos de toda su carrera, que provocó masivas críticas de difícil interpretación. ${ }^{10}$ Nuevamente, la sociedad, arrastrada por la prensa sensacionalista, omite mencionar (o investigar, en caso de ignorancia) que actitudes de este tipo no eran inauditas en el mundo del rock ni en el país. La canción Born in the USA de Bruce Springsteen fue oportunamente apropiada por Ronald Reagan para su campaña presidencial; mientras en Argentina, Carlos Gardel -que estaba por encima de los partidos políticos- canta para el dictador venezolano Gómez, apoya el golpe de Estado de Uriburu y se hace amigo de Terra durante la dictadura en Uruguay (Ruffinelli, p. 87).

Cuando la sociedad no capta la parodia, se interpretan los hechos de modo lineal: "the pragmatic ethos would be neutralized

10 Charly trató de explicarlo así: "Me pasaron cosas muy fuertes y aquí hay muchos cabos y tuve la sensación de que se me quería preguntar algo, de que el poder me quería preguntar algo que yo asumí como beneficioso. Cuando lo conocí en vivo me desarmó completamente. Yo le levanté la mano así: ey presi. ¡Ey Charly! Me levanto y me abraza y me dice "te estuve escuchando todo el día”. Me pareció muy piola tener la oportunidad de cenar y ser invitado a su casa y poder decirle lo que yo pensaba, quizás podía ayudar en algo, sobre todo teniendo en cuenta de que no era una cosa que yo la hubiera hecho para tener algún rédito, ni él, porque se estaba despidiendo del poder, se estaba yendo; y mucha curiosidad de saber cómo era eso ahí adentro. Es un tipo muy muy especial y tiene un carisma increíble y era totalmente querible. Yo también quería saber si era humano, y me pareció humano" (El karma de vivir al sur). by the refusal or inability to share the necessary mutual code that would permit the phenomenon to come into being" (Pattie, p. 94). La comprensión de estos actos requieren del lector una triple competencia: lingüística, retórica o genérica, e ideológica (Kerbat-Orecchioni en Pattie, p. 94), así como tomar en cuenta "the entire enunciative act: the text and the "subject positions" of encoder and decoder, but also the various contexts (historical, social, and ideological) that mediate that communicative act" (p. 108).

Al igual que Pinkerton, el protagonista de The Wall, Charly ha recorrido todas las etapas de la estrella de rock: la idolatría y celebridad, la autodestrucción ególatra y la trans-contextualización fascista; hasta alcanzar niveles esquizofrénicos ${ }^{11}$. Esta fractura de la personalidad unificada provoca una sensación de pérdida y de desposesión del yo, donde los significantes lacanianos -desvinculados del contexto o de la cadena de referencias que articulaba su significado- se manifiestan en su inmediatez física y concreta, y se prestan a cualquier tipo de combinación inusitada, liberada de las delimitaciones anteriormente impuestas por el discurso (Kaiero, p. 304). El mismo Charly lo deja claro cuando confiesa:

Me agarró el Síndrome The Wall, de no poder expresarme como yo quería, o tener ideas avanzadas y que me las repriman, o que me ocurren económicamente, me agarró lo que le agarró al personaje de The Wall que se convierte

11 Para ejemplificar este estado delirante, valga recordar cuando anuncia su boda con una fan de diecisiete años cuya madrina sería Mercedes Sosa y el padrino Carlos Menem. 
en una estrella de rock fachista, la época Say No More, que todavía dura, porque no renegué de eso. (Mundo Casella, 2012)

Esta fragmentación no es más que un "blending" del neoliberalismo, donde la representación de los principios morales se desdibuja, y "donde cierto desencanto moral puede aparecer como una forma de trasgresión y hasta de resistencia. Pero en ese gesto de trasgresión y resistencia siempre se rescata la validez de la creación como un espacio crítico" (Pons, p. 10). Esto refuerza la relación que se establece "between the subjectivity of the artist's biography and experience, and the objectivity of the collective narrative". Después de todo, el artista no puede parodiar si no está en contacto con el objeto parodiado.

\section{Conclusiones}

Escucho a Charly, que dice unas barbaridades re-crudas y concretas, con unas frases que en el año 5000 los arqueólogos se van a preguntar: ¿cómo todo el mundo no escuchaba a este tipo? Willy Crook

El apagón en la Ciudad de Buenos Aires en febrero de 1999 se compara en muchos sentidos al ocurrido durante el verano de 1977 en la Ciudad de Nueva York ${ }^{12}$, ambos en épocas de profunda decadencia económica y social. El sentido de abandono, alienación y aislamiento, y el de haber quedado librado a las circunstancias, son ecos de un país en el que el "sálvese quien

12 En pleno apogeo del movimiento punk, el apagón de aquel verano neoyorkino provocó saqueos de tiendas, incendios provocados por las masas, y marcó un momento decadente de una ciudad que estaba sumida en el desempleo y en una profunda crisis socioeconómica. pueda" y la fragmentación social estaban a la orden del día (Pons, p. 8). Lo que ocurrió en Argentina y en la mayoría de los países latinoamericanos durante los años noventa fue mucho más traumático y complejo que las dictaduras de los setenta y ochenta, en el sentido de que no había un enemigo al que atacar. "No sólo cambia el estado, sino también la sociedad y con ella, los valores orientadores y las instituciones de ordenamiento social" (Mancebo, p. 180). "La presencia decisiva de la paradoja democracia-exclusión en los '90 dificulta la construcción de identidades y de lógicas colectivas trascendentes" (p. 190).

Esto generó una impotencia social que debía ser expresada de alguna manera; es aquí donde surge la labor del artista, que trata de descubrir nuevas estrategias frente al poder totalitario del estado (Muíño, 2012, p. 161). Charly García inventa la estrella de rock nacional "porque fui consciente de ello. Yo fui el primero de todos los músicos que empecé a decir que era una estrella, que no era un músico, que yo era una estrella; o sea, inventé el trabajo de estrella de rock acá" (El karma de vivir al sur).

La obra de Charly García durante los años noventa estuvo revestida de nuevas formas y recursos, principalmente a través de la parodia trans-genérica, es decir, al utilizar todos los recursos artísticos, sin limitarse a la música. La primera etapa, de 1990 a 1994 (del disco Filosofia barata a La hija de la lágrima) representa una parodia por binding, enfocada en la experimentación musical, como por ejemplo su versión rock del Himno Nacional Argentino o sus discos conceptuales donde aplicó el ambient music. La segunda etapa, de 1995 a 1996 
(de Casandra Lange a Say No More) refleja una parodia por banging, donde arremete contra la cultura mediática. Finalmente, la tercera etapa va de 1997 a 1999 (de Alta fidelidad a Charly \& Charly) utiliza principalmente la parodia por blending dirigida en su totalidad a la política.

Pero los riesgos de ser una estrella mediática son grandes. Ser una figura pública en constante polémica desgasta; es ahí cuando su mera presencia se transforma en arte, representado en forma de performance. Presenciar un concierto de Charly es una experiencia performática a través de distintos niveles de parodia, ejemplos de ello se dieron cuando ingresó a un concierto en ambulancia como parodia de su internación por drogas, o cuando utilizó una muñeca Barbie como instrumento durante la grabación de su disco Hello! Unplugged (1995). En cada una de sus presentaciones o discos, las reinterpretaciones de sus éxitos ochenteros están cargadas de variaciones paródicas que dicen mucho del cambio de enemigo de una década a otra.

\section{El Sindrome The Wall que el mismo Gar-} cía crea, es una actitud fascista que parodia el sistema neoliberal, y cuando un artista performa a un político o celebridad, "the parodic blending variation has made an appearance" (Chambers, p. 243). Sin embargo, no es fácil de reconocer, y suele confundirse con una asimilación en vez de una provocación, ya que la parodia por combinación (blending) es la más compleja, y su efecto es "smooth and seamless, and it is a nearly impossible task to sort out the plural creation that emanates from some foggy border between the imitator and the imitatee" (p. 248).
Durante los noventa se quejaron de su voz (como si Bob Dylan no hubiera empeorado con los años hasta ser prácticamente irreconocible), se quejaron de los discos raros (en vez de reconocer la influencia de Brian Eno en sus producciones), de sus caóticos shows y escándalos arriba y abajo del escenario (pero que aprovechó la prensa amarillista), se quejaron de la falta de grandes éxitos, pero siguieron oyéndolo igual. Es decir, en plena etapa Say No More, ¿una institución y símbolo de la lucha social como Mercedes grabaría un disco junto a un drogadicto sin talento? Ante la polémica, ella misma salió en su defensa: "Argentina está llena de mitos que no existen. Y cuando sí existen, como Charly, se los intenta liquidar o peor aún, neutralizar" (Del Porte, 2000, p. 27).

Como dijo Spinetta en aquella época: "ahora está en un estado tipo Van Gogh, por suerte todavía tiene las dos orejas" (Mejor hablar de ciertas cosas). A Charly aún lo esperaba la primera década del siglo XXI para terminar de de-construir su mito. Si su vida y obra resultan decadentes, hay que recordar que él es la antena que capta lo que pasa a su alrededor, es por tanto, un reflejo de la realidad, que con elaboradas parodias revela su verdadero rostro; como si en la canción Say No More, Charly le respondiera a la Argentina: "Jugaste/ mentiste/ fallaste/ no viste quién soy/ Amaste/ te fuiste/ curaste/ pediste perdón/ Alguna vez/ algo tenía que pasar/ no sé si lo entenderás/ yo siempre estuve aquí/ no sé qué hiciste en mí/ porque mi vida es tan triste/ yo sé que existe la voz". 


\section{Referencias}

Alabarces, Pablo. (1997). "Santa Maradona, ascenso y caída de un mito futbolístico". La cultura en la Argentina de fin de siglo: ensayos sobre la dimensión cultural. Buenos Aires: Oficina de Publicaciones del CBC, Universidad de Buenos Aires.

Ballaré, Liliana et al. (1997). "Los intelectuales del menemismo". La cultura en la Argentina de fin de siglo: ensayos sobre la dimensión cultural. Buenos Aires: Oficina de Publicaciones del $\mathrm{CBC}$, Universidad de Buenos Aires.

Chambers, R. (2012). How to write parodies and become immortal. North Charleston, SC: CreateSpace.

Del Porte, Orlando. (2000). El aguante. Valencia: Océano: Editorial La Máscara.

Dowdy, Michael. (2013). Broken souths: Latina/o poetic responses to neoliberalism and globalization. Tucson: The University of Arizona Press.

El karma de vivir al sur. (2002). Dir. Alejandro Pels. People + Arts.

Favoretto, Mara. (2014). Charly en el país de las alegorías: un viaje por las letras de Charly García. Buenos Aires, Argentina: Gourmet musical.

García, Charly. (1999). Demasiado Ego. Argentina: Say No More/Interdisc: Polygram. . (1996). Say No More. Argentina: Say No More/Sony.

Historias verdaderas: Charly García. (2004). Dir. Luis Urbaneja. E! Entertainment Television.
Hutcheon, Linda. (2000). A Theory of Parody. The Teachings of TwentiethCentury Art Forms.

Kaiero, Ainhoa. (2014). Creación musical e ideologías: la estética de la postmodernidad frente a la estética moderna. Universitat Autónoma de Barcelona, 2007. Tomado de: https://ddd.uab.cat/record/38172.

Mancebo, Martha. (1999). La sociedad argentina de los '90: crisis de socialización. Los noventa: política, sociedad y cultura en América Latina y Argentina de fin de siglo. Buenos Aires, Argentina: Facultad Latinoamericana de Ciencias Sociales.

Mejor hablar de ciertas cosas. (1996). Dir. Javier Andrade. MTV.

"Entrevista a Charly García". Mundo Casella. (2012). Canal C5N, Buenos Aires, Argentina.

Muíño, David. (2012). Postmodernidad y (pos)dictadura. "Consideraciones teóricas sobre la literatura argentina postdictatorial". Asociación Cultural Impossibilia. Volumen 3: 150-163.

Pattie, David. (2007). Rock Music in Performance. New York: Palgrave Macmillan.

Pelfini, Alejandro. (1997). "Transformaciones sociales y perturbación cultural en la alta modernidad". La cultura en la Argentina de fin de siglo: ensayos sobre la dimensión cultural. Buenos Aires: Oficina de Publicaciones del CBC, Universidad de Buenos Aires.

Pons, María Cristina. (2014). "Neoliberalismo y literatura en Argentina: 
entre una retórica mercenaria y la autonomía de un arte crítico". Espéculo. Revista de estudios literarios. Universidad Complutense de Madrid. Tomado de: ucm.es/info/ especulo/numero41/neolibe2.html.

Quevedo, Luis Alberto. (1999). "Política, medios y cultura en la Argentina de fin de siglo". Los noventa: política, sociedad y cultura en América Latina y Argentina de fin de siglo. Buenos Aires, Argentina: Facultad Latinoamericana de Ciencias Sociales.

Rose, Margaret. (1993). Parody: ancient, modern, and post-modern. Cambridge UP.

Rossi, María José. (1997). “Arte y posmodernidad: la estética de los '90". La cultura en la Argentina de fin de siglo: ensayos sobre la dimensión cultural. Buenos Aires: Oficina de Publicaciones del CBC, Universidad de Buenos Aires.

Rufinnelli, Jorge. (1997). "La sonrisa de Carlos Gardel". La cultura en la Argentina de fin de siglo: ensayos sobre la dimensión cultural. Buenos Aires: Oficina de Publicaciones del CBC, Universidad de Buenos Aires.
Sarlo, Beatriz. (1994). Escenas de la vida posmoderna: intelectuales, arte $y$ videocultura en la Argentina. Buenos Aires: Ariel.

Semán, Pablo y Vila, Pablo. (1999). "Rock chabón e identidad en la Argentina neoliberal". Los noventa: política, sociedad y cultura en América Latina y Argentina de fin de siglo. Buenos Aires, Argentina: Facultad Latinoamericana de Ciencias Sociales.

Till, Rupert. (2010). "Pop Stars and Idolatry: An Investigation of the Worship of Popular Music Icons, and the Music and Cult of Prince". Journal of Beliefs \& Values. 31.1: 69-80.

Wilson, Timothy y Favoretto, Mara. (2011). Actuar para (sobre) vivir: rock nacional y cumbia villera en Argentina. Studies in Latin American Popular Culture. Volume 29. 
